\title{
Ancient DNA set to rewrite human history
}

\section{Discovery that some humans are part-Neanderthal reveals the promise of comparing genomes old and new.}

The worlds of ancient and modern DNA exploration have collided in spectacular fashion in the past few months. Last week saw the publication of a long-awaited draft genome of the Neanderthal, an archaic hominin from about 40,000 years ago $^{1}$. Just three months earlier, researchers in Denmark reported the genome of a 4,000-yearold Saqqaq Palaeo-Eskimo ${ }^{2}$ that was plucked from the Greenland permafrost and sequenced in China using the latest technology.

As researchers compare these ancient genomes with the ever-expanding number from today's humans, they expect to gain insights into human evolution and migration - with more discoveries to come as they decipher DNA from other branches of the human evolutionary tree. "For the first time, ancient and modern genetic research is going hand in hand," says Eske Willerslev, whose team at the University of Copenhagen led the Palaeo-Eskimo sequencing project. "It is really a fantastic time."

Already, analysis of the Neanderthal genome has helped to resolve a debate about whether there was interbreeding between Neanderthals and Homo sapiens: genome comparisons suggest that the two groups mated an estimated 45,00080,000 years ago in the eastern Mediterranean area. The sequencing study, from a consortium led by Svante Pääbo of the Max Planck Institute

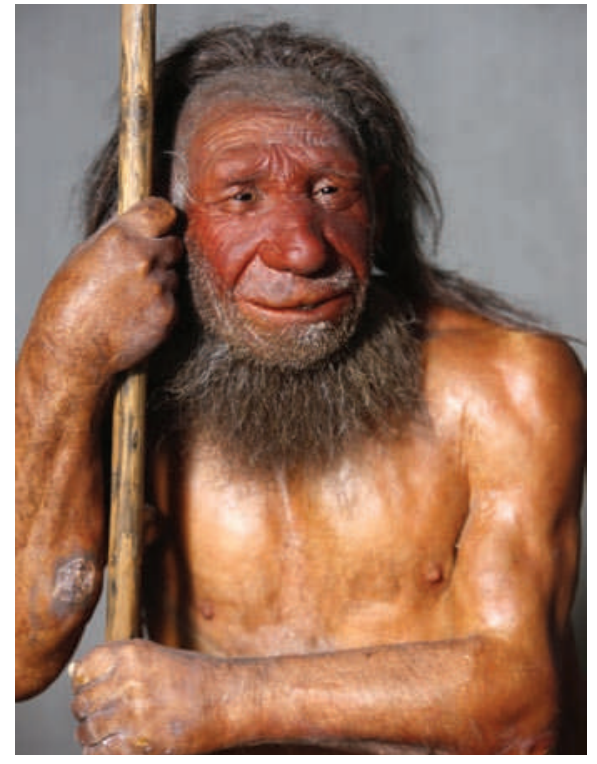

Neanderthals once bred with Homo sapiens.

for Evolutionary Anthropology in Leipzig, Germany, found that the genomes of nonAfrican H. sapiens today contain around 1-4\% of sequence inherited from Neanderthals.

The breakthroughs have been driven by the plummeting cost of sequencing, together with new strategies for reducing or detecting contamination by near-identical modern human DNA. These days, labs such as Pääbo's and Willerslev's might piece together a complete genome from the degraded scraps of DNA present in ancient bone, hair or teeth in as little as a month. Researchers from geneticists to fossil specialists can't wait for more.

Some hope to use ancient-modern genome comparisons to chart splits in human populations and how they might have correlated with climatic changes. "I call this molecular stratigraphy," says Jeffrey Long, a genetic anthropologist at the University of New Mexico in Albuquerque. "I then want to use this relative chronology of genetic events to compare to the palaeoclimate of Earth's biomes."

For Willerslev, ancient genomes offer the opportunity to trace prehistoric migration routes. By comparing the ancient Saqqaq genome with those of modern human populations, Willerslev and his team linked it to the present-day Chukchi people of Siberia, revealing that ancestors of this group trekked from eastern Siberia to Greenland about 5,500 years ago. "The genomes will allow us to test theories about peoples and migrations debated for a century," says Willerslev. "In the next five years, we will see a whole spectrum of discoveries." For example,

\section{China and Taiwan strengthen academic ties}

After a year of debate that on several occasions descended into fisticuffs, Taiwanese legislators this week opted for pragmatism over nationalism and put the finishing touches to amendments that will allow about 2,000 mainland Chinese students to enter Taiwan's graduate and undergraduate university programmes every year. The change, to be finalized this month, will open the door to a large and much-needed pool of young minds for Taiwan's universities as early as this autumn.

Taiwan has strong research universities but a shortage of students. Many mainlanders already head to Taiwan for postdoctoral studies, and some go as short-term graduate or undergraduate exchange students. But, thus far, Taiwanese law has barred them from graduate or undergraduate degree programmes.

Taiwan's Chinese Nationalist Party government proposed relaxing these rules more than a year ago, as part of a warming relationship that has seen increased business and transportation links with mainland China. But, fearing that both the universities and the workforce could be overrun by mainlanders, opposition party members resisted, with some resorting to grappling a speaker to the floor of the legislature last month in an attempt to block the motion. On 10 May, violence broke out again before a subcommittee finalized the amendments.

Many scientists see the plan as an opportunity to keep the island internationally competitive. "The talent and the hard-working attitude in general of the mainland students will be a boost to research," says Ben Chao, dean of the Earth sciences college at Taiwan's National Central University in Jhongli City. Kuo-Fong $\mathrm{Ma}$, a seismologist at the university, says that it will also benefit science on the mainland. Taiwan has a strong record in earthquake early warning systems, for example, and educating mainland students could help to establish more research collaborations and transfer knowledge that could benefit the whole of China.
An explosion in the number of universities in Taiwan - from 40 to 175 during the past 20 years along with a declining birth rate means that there are plenty of places available for mainlanders: about 55,000 by 2015 , according to census figures. And there will be no shortage of applicants, says Cong Cao at the Levin Institute in New York, who studies China's science and technology manpower issues. He points out that students will not suffer the language problems or culture shock that study abroad could bring. "Moreover, professors at Taiwan's universities are more serious about advising students," Cao argues.

But the amendments still bar 
the work could reveal whether the first Native Americans included migrants from Europe who crossed the ice-age Atlantic Ocean.

Pääbo and his team had nearly completed the Neanderthal genome by early 2009, about four years after the sequencing effort began. But, to carry out their analysis, the researchers raced to sequence five genomes of people from diverse modern populations in Europe, Asia and Africa. By comparing these to the Neanderthal genome, they found 78 protein-altering sequence changes that seem to have arisen since the divergence from Neanderthals several hundred thousand years ago, plus a handful of other genomic regions that show signs of positive selection in modern humans. These are linked to sperm motility, wound healing, skin function, genetic transcription control and cognitive development. The team also found that only the modern African genomes lacked segments of Neanderthal ancestry, indicating that interbreeding between the two groups probably occurred after humans migrated out of Africa.

That revelation is likely to revive the debate about whether or not the two groups are separate species, says anthropologist Fred Smith of Illinois State University in Normal, who has studied Neanderthals in Europe. Smith thinks that they are a subspecies of $H$. sapiens. Now that the genomes can be compared, it will be possible to investigate the genetic roots of some shared features. For instance, he points to the development of the occipital bun, a bulge at the back of the skull that is found in Neanderthals and in some modern humans. "We need to look and clarify certain characteristics in Neanderthal morphology with genetics," he says.

Most researchers in the field anticipate that the next ancient human genome will be completed by Pääbo's group, from a tiny finger bone found in a cave in the Altai Mountains in southern Siberia. In March, the group reported the mitochondrial DNA sequence from this individual ${ }^{3}$, an unknown hominin that, so far, does not genetically match
derthals or $H$. sapiens and may ither Neanderent a new species. The team dated the bone to about 40,000 years ago, but others say that the sediments around the bone may be as old as 100,000 years. There is speculation that the bone could be the remains of an older species of Homo, perhaps even of a remnant population of Homo heidelbergensis, known in Europe from 300,000 to 500,000 years ago, or of Homo erectus, found as early as 1.8 million years ago from Africa to Indonesia. A full sequence may help to resolve this.

Obtaining the genome of a human ancestor this old was previously unimaginable. "I honestly believe this new era will change our view of human evolution," Willerslev says. Rex Dalton

1. Green, R. E. et al. Science 328, 710-722 (2010).

2. Rasmussen, M. et al. Nature 463, 757-762 (2010).

3. Krause, J. et al. Nature 464, 894-897 (2010).

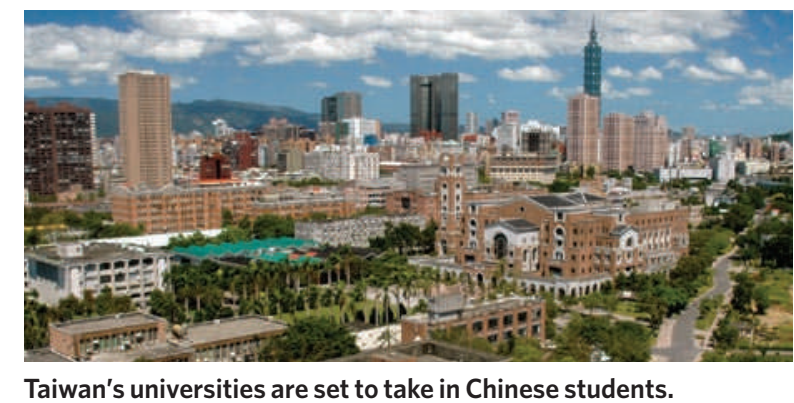

Taiwan's universities are set to take in Chinese students.

the major national universities

from accepting Chinese undergraduates - a big caveat - and withhold Taiwanese government scholarships from mainlanders. This is a potential deal breaker, says Xiao-fan Wang, a cancer biologist at Duke University in Durham, North Carolina, and the first mainland-born scientist to be president of the Society of Chinese Bioscientists in America, a formerly Taiwanesedominated academic networking group (see Nature 459, 1044; 2009). Wang says that when Hong Kong opened up to mainland students, scholarships were a big draw. "I am not sure there will be a flood of students who want to go to Taiwan," he says. Yi Rao, dean of the life-sciences school at Peking University in Beijing, adds that many mainland students prefer to do graduate work at US universities.

Andrew Wang, vicepresident of Taiwan's premier scientific institute, Academia Sinica, says that mainlanders may be wary of returning from Taiwan with a freshly minted diploma bearing the phrase 'National Taiwan University' a rubric that challenges Beijing's assertion that Taiwan is part of China, and not an independent nation. There is also concern that if places at top universities are held for mainland graduate students, Taiwanese people might feel slighted. “These issues have to be worked out before we move ahead," says Andrew Wang.

David Cyranoski 
the 2007 map track infections by just one malaria parasite, $P$. falciparum, which carries the highest disease burden. And the analysis does not take into account some parameters that are likely to change as a result of global warming, such as rainfall patterns and human migrations.

Nevertheless, the results largely match those of several other recent studies, including one published last year by Kevin Lafferty of the US Geological Survey in Santa Barbara, California, which also concluded that rising temperatures over the last century had no net impact on the incidence of malaria (K. D. Lafferty Ecology 90, $888-900 ; 2009)$. In 2000, models designed by David Rogers and Sarah Randolph at the University of Oxford predicted that although some parts of the world would gain malaria because of climate change, large areas would see a drop in disease due to reductions in rainfall and humidity (D. J. Rogers and S. E. Randolph Science 289, 1763-1766; 2000). The result: no net difference.

"The complexity of malaria and the other vector-borne diseases is astonishing," says Reiter. "To bring it down to just one factor climate change - is totally unjustifiable."

The same could hold true for other diseases that rely on intermediate vectors like mosquitoes. Dengue fever, for example, has also been touted as an infectious disease that could get a boost from climate change. The virus, which is carried by mosquitoes, is already on the march, and is spreading more rapidly into the southern
United States. But the impact it will have there is likely to be minimal compared with that in less developed regions of the world because of lifestyle differences, says Reiter. Americans spend more time indoors, he says, and are more likely to have window screens to keep mosquitoes out.

Laura Harrington, who studies mosquitoborne diseases at Cornell University in Ithaca, New York, agrees. "In the context of vectorborne diseases, climate change is probably going to have a minimal role in comparison to other factors," she says. Even so, Gething's results are likely to be controversial, cautions Richard Ostfeld, a disease ecologist at the Cary Institute of Ecosystem Studies in Millbrook, New York. Although global analyses such as Gething's are useful, he says, they may miss important regional trends - such as the spread of mosquitoes from the lowlands to the highlands of eastern Africa, which some argue is the result of rising temperatures. "There's a pretty strong spatial disconnect between areas where there is strong economic development and increasing control of mosquitoes, versus those areas where the risk of climate-induced disease is highest," he says.

Others worry that the results of the study will be misinterpreted. "On smaller scales, climate change certainly has big effects on disease," says Harrington. "This does not diminish the importance of climate change at all."

Heidi Ledford this increase is an underestimate. More than $90 \%$ of the catch is less than two years old. "The increasing juvenile catch is increasing the risk of population collapse," says Hsu. "The population is dropping for all age classes and we see signs of serious problems if no management measures are set immediately."

Responding to concerns about the health of the stock, Japan's Fisheries Agency last week outlined new measures to monitor and manage the tuna populations. These specify limits on the weight of fish that each boat can catch, restrictions for the large boats using encircling nets that account for most tuna fishing, along with new requirements for other boats to report their catches. And fish farmers, who collect an increasing but unknown number of juveniles and raise them in pens, will be required to register and report their activities. The agency plans to implement the restrictions by April 2011.

The measures also call for better information on juvenile stocks and spawning areas, and for the establishment of an international network of researchers to study and manage Pacific bluefin tuna fisheries. "To protect these spawning regions, we have to find out where they are and when the peak seasons are. Then we can start to make restrictions on which ones can be fished and when they can be fished," says Yukio Takeuchi, a researcher at the National Research Institute of Far Seas Fisheries, an arm of the Fisheries Agency based in Shizuoka, Japan, who chaired the ISC working-group report.

Katsukawa says that the new measures, "if done effectively", could have a major impact. But he fears they will be implemented too slowly to head off an irrecoverable drop. "It could happen suddenly, but we won't see it until it happens." David Cyranoski

\section{Corrections}

The News story 'China and Taiwan strengthen academic ties' (Nature 465, 148-149; 2010) incorrectly stated that Xiao-fan Wang is the first mainland-China-born president of the Society of Chinese Bioscientists in America. In fact, he is the first president to be born, raised and educated under the communist government of the People's Republic of China.

The News Feature 'Life after death' (Nature 465, $150-155 ; 2010$ ) misspelt the name of Debra Moriarity throughout. 